EPJ Web of Conferences 98, 05003 (2015)

DOI: $10.1051 /$ epjconf/ 20159805003

(C) Owned by the authors, published by EDP Sciences - SIF, 2015

\title{
Energy situations in Japan before and after the Fukushima nuclear accident
}

\author{
K. Muraoka \\ Kyushu University $\left(^{*}\right)$ and Plazwire Co., Ltd. - 2-3-54 Higashi-naka, Fukuoka 812-0892, Japan
}

\begin{abstract}
Summary. - This article describes the various effects on the public conception on nuclear energy and more generally on energy policies in Japan due to the nuclear accident that occurred on 11th March 2011 at the Fukushima Dai-ichi nuclear power station, which is owned and operated by Tokyo Electric Power Company (TEPCO). Before the accident, nuclear energy had been conceived as the main energy source of electricity in Japan for reducing $\mathrm{CO}_{2}$ emission beyond 2020. However, public opinion has turned almost completely against nuclear energy after observing how vulnerable the nuclear system had been. The present Japanese government is now trying to buy time before taking a decision. After explaining these circumstances, the author tries to chart his personal projection of energy sources for Japan to 2050.
\end{abstract}

\section{1. - Introduction}

The Fukushima Dai-ichi nuclear accident has had deep and different impact on each individual not only in Japan but worldwide. The author wants to present his views on the impact in this article by the following structure: sect. $\mathbf{2}$ describes the Fukushima Dai-ichi nuclear accident, triggered by the earthquake and the subsequent tsunami on 11th March 2011, namely the accident itself, the number of casualties, the size of the affected areas, and the background leading to the accident by mainly referring to four reports (by the investigation committees of the National Diet [1], the Government [2], an independent

$\left(^{*}\right)$ Professor Emeritus.

This is an Open Access article distributed under the terms of the Creative Commons Attribution License 4.0, which permits unrestricted use, distribution, and reproduction in any medium, provided the original work is properly cited. 


\section{EPJ Web of Conferences}

group [3], and TEPCO [4]). The Japanese energy policy that was in place before the accident is briefly reviewed in sect. 3 to try to highlight the fact that the governments had been trying to reduce $\mathrm{CO}_{2}$ emission by heavily depending on nuclear energy. In sect. 4, the national nuclear policy during the three years after the accident is described to highlight opinions of swinging from the complete abolition of nuclear energy in the near future to the resumption of operation of nuclear reactors. This is due to the change of the governments in the two national elections in 2012 (the Lower House) and 2013 (the Upper House). During these three years, public opinion has been heavily against nuclear power, with opponent rating, as far as the author has been aware, above $70 \%$ in opinion polls. The fundamental energy plan [5], approved by the present government at a cabinet meeting in April 2014, is thus a compromise between the pro- and anti-nuclear energy groups in the ruling government formed by a coalition of two parties, defining nuclear energy as the energy source to support "the base load" of electricity.

Against this background, sect. 5 is devoted to explaining the author's personal projection of energy sources for Japan to 2050, using "numbers" for quantitative discussions for relevant physical quantities in the unit of $\mathrm{kWh} /$ person/day, which was first introduced by David MacKay in his very interesting and enlightening book [6]. Finally a brief summary will be presented in sect. 6 .

\section{2. - The Fukushima nuclear accident triggered by the earthquake/tsunami on 11th March 2011}

Let us start with a personal experience. At 14:46 on Friday 11th March 2011, the author was working in his office at Chubu University, near to Nagoya, which is situated about $300 \mathrm{~km}$ south-west of Tokyo, and was packing books and materials to be sent back home to Fukuoka in preparation for his imminent retirement from the University at the end of March. After feeling a strong earthquake, another professor dashed from his room on the fourth floor of a building in the University dashed by in order to escape to a nearby car park in case of collapse of the building. The Nagoya area has been well known for a long time to be prone to heavy casualties from strong earthquakes occurring every 70-80 years (by the name of the "South-east sea giant earthquake area"). The last big one was in 1944 with a magnitude of about 8.0 on the Richter scale, resulting in more than 20000 people killed and missing and more than 30000 completely destroyed houses. Therefore, the people in that area have feared an imminent big earthquake to come anytime in the near future, and the behavior of the neighboring professor is easily understandable.

About an hour and a half after the earthquake, a professor next to the author's office came in to say that he had seen on the internet that the epicentre had been in the Pacific Ocean about $200 \mathrm{~km}$ off the Tohoku area and that the coastal area had been badly hit by the subsequent tsunami. The devastated area was located about $300 \mathrm{~km}$ north-east of Tokyo. At about the same time, the intensity of the earthquake at the Nagoya area was reported to have been 4 in the JMA (Japan Meteorological Agency) seismic intensity scale, which was equivalent to VI in the MM (Modified Mercalli) intensity scale. The 


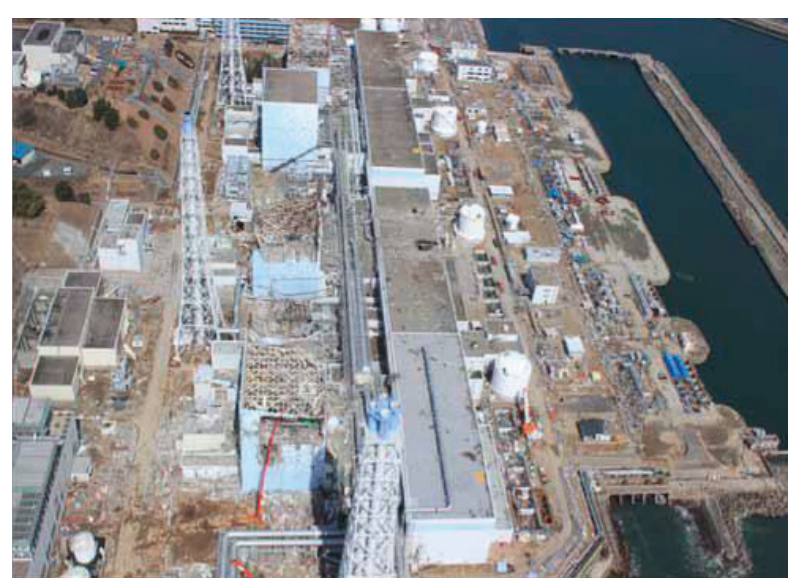

Fig. 1. - View (from south) of Fukushima Dai-ichi Units 1, 2, 3, and 4 from the top to bottom, just after the accident [1].

author could easily imagine from the tremor he felt at about $500 \mathrm{~km}$ away how devastating the earthquake would have been in the area close to the epicenter.

Of course, the results of the earthquake and the subsequent tsunami were devastating (the 4th biggest earthquake in the world in recorded history), with the number of people killed and still missing now totaling to about 20000 and the number of houses completely destroyed being about 127000 and partially destroyed about 272000 (It is to be noted that these numbers were mostly casualties and damages by tsunami itself, as evidenced from the following numbers of dead and missing people in different prefectures: about 2000 in Fukushima Prefecture, about 11000 in Miyagi Prefecture, and about 6000 in Iwate Prefecture. Casualties resulting from the nuclear accident are described in sect. 24 ).

However, the effect of the Fukushima Dai-ichi nuclear accident, resulting from the earthquake and the tsunami, has turned out to be much longer lasting, which has manifested itself as having had a revolutionary influence on energy policies not only in Japan but worldwide.

Figure 1 is a photograph taken just after the accident, shown in one of the reports [1] from the four investigation committees described in sect. $2 \cdot 1$ below. The aftermath of hydrogen explosions in the Units 1,3 , and 4 can be seen clearly.

The following numbers [7] may be frightening enough for anybody:

- The number of people who had been living in the three affected zones (shown below) and who have had to be evacuated remains at 81291 (as of 1st October 2013)

- Three zones totaling $1150 \mathrm{~km}^{2}$ are identified as affected areas as follows:

(1) The area of $337 \mathrm{~km}^{2}$ where it is impossible to live in the near future,

(2) The area of $304 \mathrm{~km}^{2}$ that is accessible but not livable, and

(3) The area of $509 \mathrm{~km}^{2}$ that is to be prepared for living in the near future. 


\section{EPJ Web of Conferences}

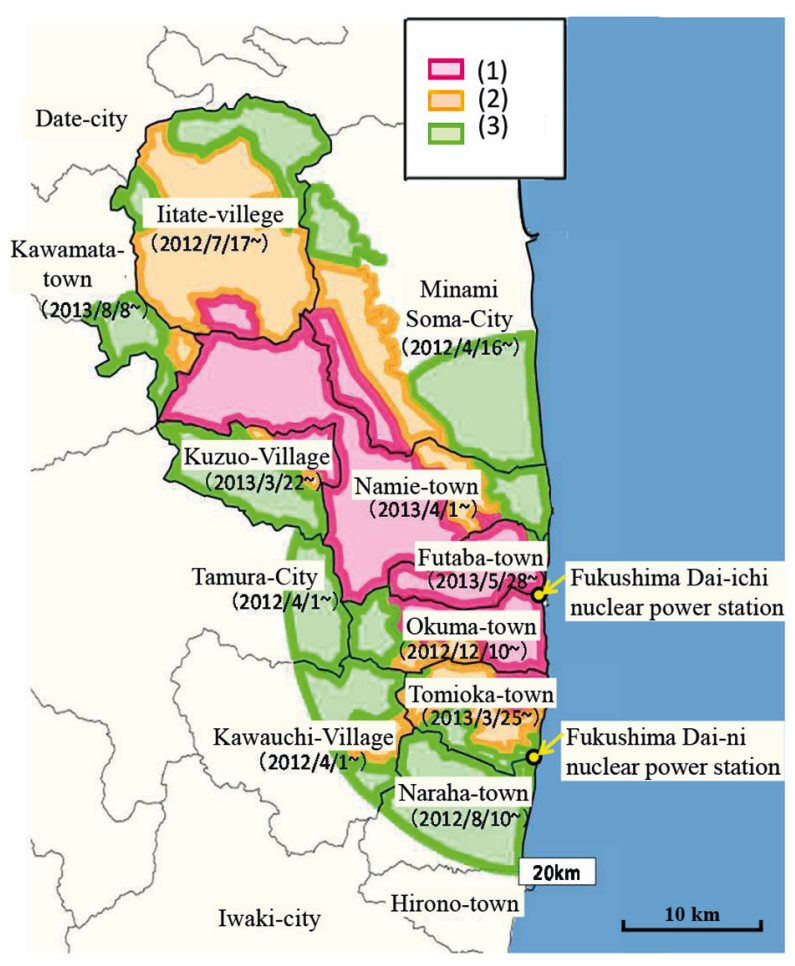

Fig. 2. - The three zones (1), (2), and (3), as described in the text [7]. The date for each village/town indicates when each zone decision was made.

The definitions of these three zones are (1) a yearly radiation dosage of more than $50 \mathrm{mSv}$ (not expected to decrease below $20 \mathrm{mSv} / \mathrm{y}$ after 6 years from the accident), (2) a yearly radiation dosage between $20 \mathrm{mSv}$ and $50 \mathrm{mSv}$, and (3) a yearly radiation dosage below $20 \mathrm{mSv}$. These zones are shown in fig. 2, together with the predicted decays of the yearly dosages for the three zones in fig. 3 .

There were 6 reactors at the Fukushima Dai-ichi nuclear stations, named as Units 1-6. All were of the type of the boiling-water reactor (BWR). Units 1, 2 and 3 were in operation and 4-6 were under regular maintenance at the time of the earthquake. The earthquake triggered the scram systems for Units 1-3 to insert the control rods into the reactor cores to shut down chain reactions there. This happened as intended. However, even after the reactors had been shut down, they still required active cooling to remove the decay heat, amounting at shutdown to about $6 \%$ of the normal thermal power output of each reactor. Loss of grid electricity due to the collapse of the transmission towers leading to Units 1-4 by the earthquake had automatically triggered the emergency diesel generators to power the reactor cooling systems, but the generators were put out of action by the tsunami which arrived at the power station some 50 minutes after the initial earthquake. The $14 \mathrm{~m}$ high tsunami overwhelmed the plants' seawall, which was 


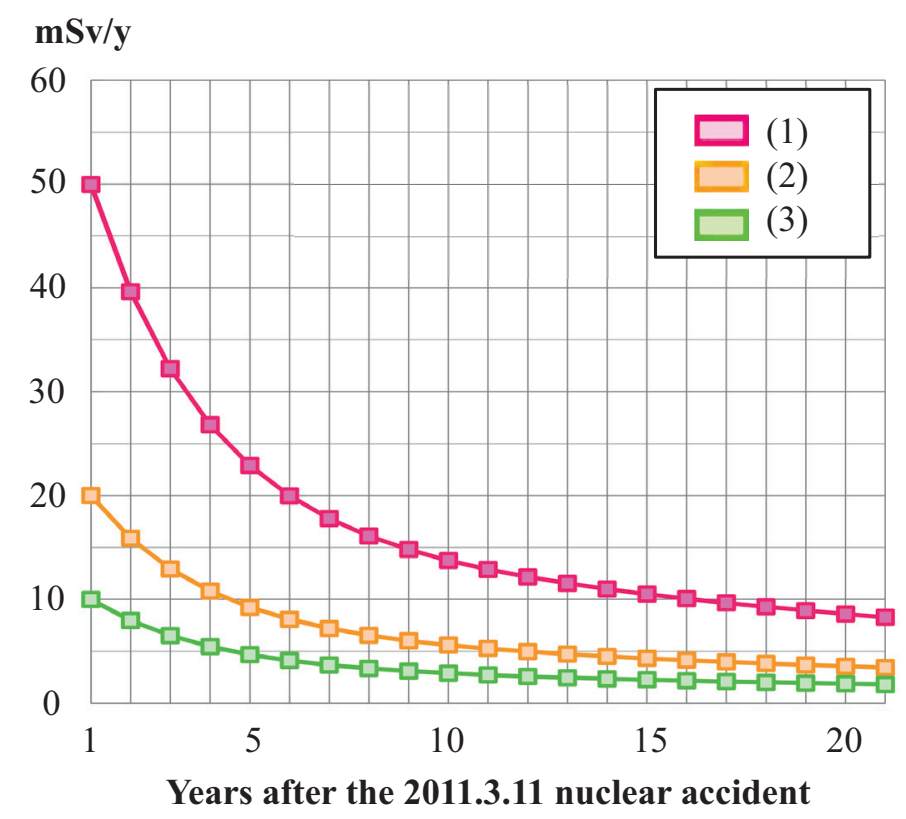

Fig. 3. - Prediction of the yearly dosages for the three zones after the numbers of years from the 2011 nuclear accident [7].

only $10 \mathrm{~m}$ high, and the rooms housing the emergency diesel generators and most of the auxiliary batteries were inundated. After this period, Units 1-3 experienced different histories due to different actions (or rather, "inactions") of the emergency cooling systems driven by the steam pressures themselves, which managed to somehow remain operational even after the tsunami assault. These were the IC (isolation condenser) for Unit 1, the RCIC (reactor core isolation cooling system) for Units 2 and 3 and the HPCI (highpressure coolant injection system) for Unit 3. In the end, however, the reactor cores of all three Units had been overheated due to one reason or another [1] and had melted down, so that the zirconium cladding of the fuel elements reacted with water to produce hydrogen gas. The gas had built up to dangerous concentrations in the reactor buildings, and this resulted in successive explosions of the buildings for Units 1 at 15:36 on 12th March, for Unit 3 at 11:01 am on 14th March, and for Unit 4 at around 6:10 am on 15th March. The explosion of the building of Unit 4 is believed to have been caused by hydrogen leaking through a common air duct with Unit 3. The containment vessel of Unit 2 was ruptured but gas accumulation did not occur as the earlier explosion of Unit 1 had damaged the side panel of the building already. These events caused severe contamination of the surrounding area due to release of radioactive materials, with the release of $(6.3-7.7) \times 10^{17} \mathrm{~Bq}$ (almost as much as $5.2 \times 10^{18} \mathrm{~Bq}$ released at Chernobyl).

Figure 4 illustrates the temporal developments of radiation dosage measured using a monitoring car around the Fukushima Dai-ichi station in the days following the accident. 


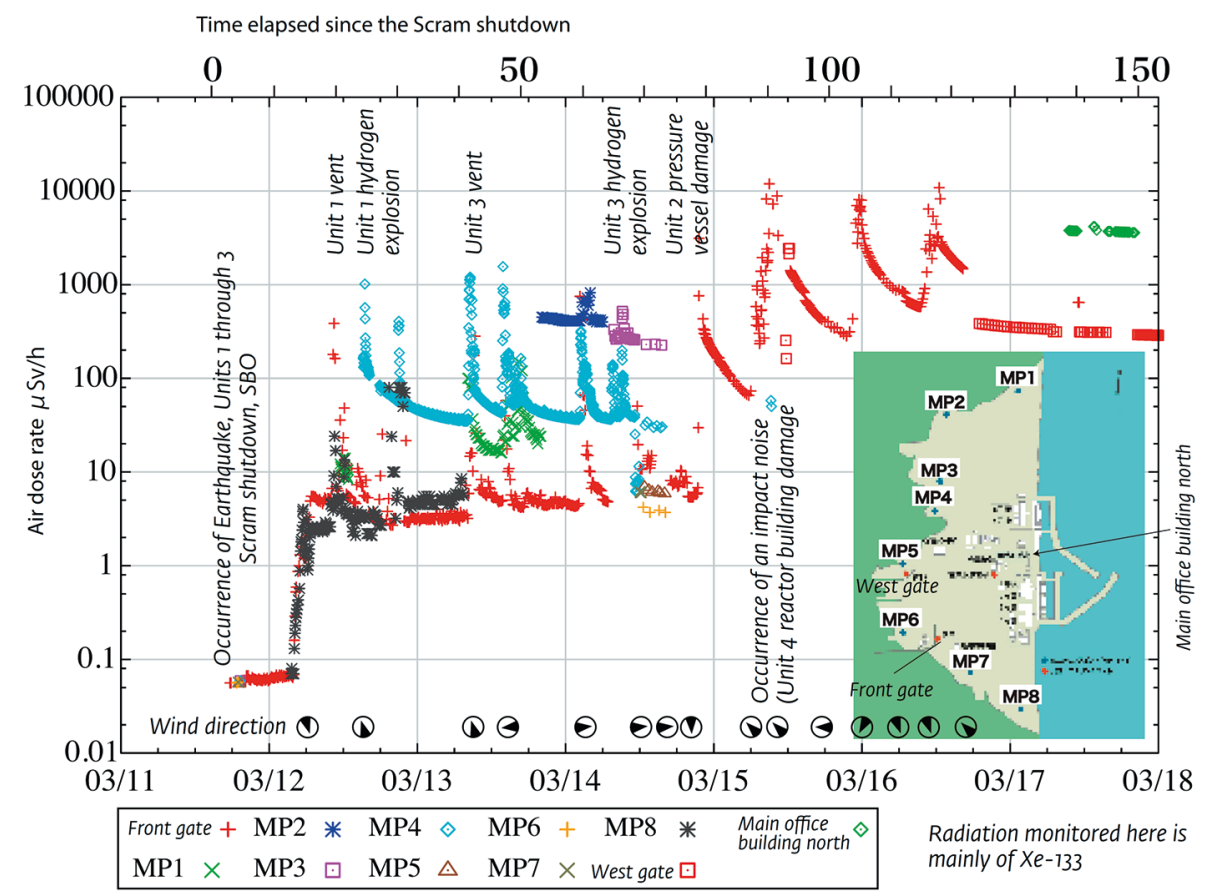

Fig. 4. - Radiation dosage measured by a monitoring car in and around the Fukushima Dai-ichi nuclear power station during the first few days after the nuclear accident [1]. Note the unit of the ordinate at $1000 \mu \mathrm{Sv} / \mathrm{h}(=1 \mathrm{mSv} / \mathrm{h})=8.76 \mathrm{~Sv} / \mathrm{y}$, which is above the fatality level for humans if the dosage continues at this level for one year.

As can be readily seen, the air dosages showed rapid spikes following various accidental and artificial events, such as hydrogen explosions and venting of suppression chambers. The most heavily contaminated zone, evident in fig. 2 extending north-west for more than $30 \mathrm{~km}$ from the Fukushima Dai-ichi station, was caused by the release of radioactivities in the period from 14th to 15th March, most probably due to rupture of the containment vessel of Unit 2, combined with a south westerly wind and rain, which resulted in the radio-activity being deposited on the ground and vegetation. At one stage of the development of the event, around 14th-15th March, namely three to four days after the earthquake/tsunami, it was feared that the situation would escalate beyond control. The then prime minister wrote in his memoir [8], published about one and a half years after the accident, that he remembers the period as "nightmarish", fearing the loss of one third of the land of the country, including the capital Tokyo area necessitating the evacuation of 50 million people, almost half of the nation's population.

By heroic efforts of workers at the nuclear power station, this "worst-case scenario" was avoided. The near threat of it was revealed about one year later as the chairman of the Japanese Atomic Energy Commission had reported to the prime minister on 23rd March 2011 [8]. Nevertheless, the subsequent results from the melt-down of the three 


\section{LNES 2014}

reactors were bad enough that the accident was subsequently listed as grade 7 , equivalent to the Chernobyl nuclear accident in 1986. More than three years after the accident, the power station and the surrounding area are still being contaminated with underground water coming into the damaged reactors, requiring thousands of large tanks to store the water with still some spilling into the Pacific Ocean. It is anticipated that it will take several decades until the decommissioning activities of the reactors will be finished.

$2 \cdot 1$. Reports of four investigation committees. - After the accident, four investigation committees were set up; namely two committees independently nominated by the National Diet and by the Government, an independent group forming its own committee, and finally the TEPCO committee. Each issued the final report from February to July in 2012 [1-4].

There is no space to go into details of the contents of these four reports, but the author would like to point out that the reports from the first three committees look impartial. On the other hand, many people have criticized the TEPCO report as trying to emphasize the scales of the earthquake and the tsunami to have been completely beyond imagination. The report includes phrases such as "We followed the prediction made by the Japan Society of Civil Engineers for any possible scale of tsunami" or "Our decision at each stage was checked by the Nuclear Energy Regulation Agency", thereby sounding like excusing/rationalizing their past behavior. Subsequently, the new nuclear management team in TEPCO issued an overall reassessment of the past situations, criticizing their own behavior/management and looking for their future [9].

Naturally there are common features in the four reports, such as the main causes of the nuclear accident were SBO (the station black-out) caused firstly by the earthquake which had destroyed the electricity transmission towers leading to the nuclear station and secondly by the tsunami which had inundated the emergency diesel and battery power areas, and finally heavily damaged/destroyed roads leading to the power station which had badly hampered the delivery of repair parts to the station. However, there were differences of emphasis of each report, such as contradictory descriptions being made for any damage in the reactor pipings due to the earthquake itself before the arrival of the tsunami $[1,2]$.

All four reports cited necessary measures to prevent a similar accident occurring again, the most conspicuous from the first three reports being the proposal of complete independence of the future nuclear regulatory body from the agency responsible for promoting the nuclear energy policy in Japan. This point is discussed in more detail in the next section.

Subsequently, many studies have been carried out and resulting reports from various organizations have appeared, including the one from Japan Society of Nuclear Engineers [10].

2'2. "Made in Japan" and "Japanese culture". - The most frequently quoted phrases from the four reports may be those by Professor K. Kurokawa, the Chairman of the committee nominated by the National Diet [1], who wrote in his "Message from the 


\section{EPJ Web of Conferences}

Chairman" that "This was a disaster Made in Japan" and "The fundamental causes are to be found in the ingrained conventions of Japanese culture: our reflexive obedience; our reluctance to question authority; our devotion to 'sticking with the program'; our groupism; and our insularity" (the underlining _ is by the author). He argues that if these attitudes were the case and could not be changed, Japan would not be entitled to have the capability of operating nuclear reactors any more.

One of the government committee members [3] stated that there exist three elements to be considered separately and independently to prepare for imminent accidents of nuclear power stations; first "The nuclear power system" to prevent any failure, secondly "Support systems in case of an accident" such as communications and transportations, and thirdly the need of preparations for "Residents and their evacuations".

All three of the investigation reports emphasized the complete lack of the first element, but the more serious was the total lack of preparations of any meaningful measures for the second and the third elements. This had been brought about because every decision with regard to the nuclear energy policy was carried out by the inner-circle people, completely shrouded from the outside world. These inner-circle people have now become commonly coined "Residents in Gensiryoku-mura (a village where residents are all associated with nuclear energy)". They had treated nuclear power stations as "absolutely safe, because they are protected by many layers of safety measures". They emphasized this argument to the extent that the possibility of any severe nuclear accident happening was false and maintained that a Chernobyl-type accident could never happen in Japan because the reactor type was completely different. This reasoning and arguments naturally lead to almost complete negligence of or being very reluctant to prepare for the above second and third elements. This attitude has since been called as "The security myth surrounding nuclear energy".

This is what Professor Kurokawa intended to convey in his Message above, which he recently (March 2014) reiterated at a press conference organized by overseas correspondents stationed in Japan after observing the developments of the past three years since the accident, when the present government had been trying to resume reactor operations without paying due attention for finding the true cause(s) of the accident. The newlyformed Nuclear Regulation Authority (NRA) only tries to check whether the above first element has been satisfied to "The strictest sense in the world" (the phrase by government officials), while the second and the third elements have been left to other organizations, such as local governments. In his eyes, the lessons from the accident seem not to have been learned sufficiently for the resumptions of reactor operations.

Whether Japan can overcome the accident "Made in Japan" out of "Japanese Culture" or not has to be carefully watched.

2:3. Actions and reactions worldwide. - After such a devastating accident, all countries in the world which have been employing or trying to introduce nuclear energy have naturally spent a great deal of time and effort to digest the event and to learn from it. We may group these countries into three, namely the first group which has decided to completely abolish nuclear power in the very near future, the second group which tries 
to keep nuclear power at a reasonable level after tightening the grip of regulations, and the third group which tries to accelerate the introduction of nuclear energy in order to cope with their fast rising energy demands. The first group includes Germany, Italy (already since after the Chernobyl accident), Belgium and Switzerland. The second group includes most other industrialized countries such as USA, France and Britain, and the third group consists of emerging economies, such as China and India, together with fast developing countries, such as Vietnam, Turkey and others. Japan seemed set to follow the German path just after the accident because of the overwhelmingly antinuclear sentiment among people. However, the change of the ruling government in the Lower House in December 2012 has resulted in a complete changeover. We will come back to this point in sect. 4 , after explaining in sect. $\mathbf{3}$ the Japanese energy policy before the 2011 nuclear accident.

Since its foundation in 1957, the International Atomic Energy Agency (IAEA) has been playing an important role in accelerating and enlarging the contribution of atomic energy to peace, health and prosperity throughout the world. As such, it was natural to try to grasp the events that occurred during and after the Fukushima Dai-ichi nuclear accident [11]. The Action Plan for defining a program of work to strengthen the global nuclear safety framework was defined in September 2011 [12]. Twelve main actions were listed, such as assessments of the safety vulnerabilities of nuclear power stations in the light of the accident and strengthening of safety standards and ensuring their implementations. The first annual report on progress on the Action Plan was submitted to the IAEA Board of Governors and the General Conference thereby determining the agenda for further developments in 2012-2013 [13]. Continued effort has been made to further implement the Action Plan.

$\mathbf{2}$ 4. After more than three years. - On the third anniversary of the accident, there were many events on 11th March 2014 to mark the earthquake/tsunami and the nuclear accident, in national/local government-organized and NGO organized ones with news media intensively covering them with special reports. At the same time, there appeared many publications covering the real and/or fundamental cause of the nuclear accident. The most commonly referred to is the comparison of the behavior of leaders before and during the Second World War with the one of before and during the crises of the nuclear accident [14]; namely, poor top-management and government officials contrasting against brave and well-trained soldiers/workers at both fields.

On the other hand, there are still about 140000 persons evacuated from their homes, including people directly affected by living in the three zones as described earlier and those evacuated voluntarily due to their concerns about radiation exposure, many of whom remain unable to see good prospects of returning home in the near future. There was no direct loss of life due to radiation exposure during and after the 2011 accident, but there are about 30 workers on site whose radiation level exceeded $100 \mathrm{mSv}$ and about 90 residents who needed treatment for their contamination by radiation. In addition, there have been the deaths of about 60 people, mostly elderly, due to stress during evacuation into temporary housing. 


\section{EPJ Web of Conferences}

The present government now says that nuclear reactors, whose safety will be guaranteed by the newly formed Nuclear Regulation Authority, should be allowed to resume operation if the local government where each reactor is located approves this. At the same time, the government is trying hard to export nuclear reactor systems, including the training of operational personnel, to emerging countries with acute energy shortages.

Because public opinion is so strongly anti-nuclear while the government is in essence trying to keep nuclear energy in the foreseeable future, it looks very difficult to come to any conclusion with good reasoning and consensus about the energy policy in Japan in the near future.

\section{3. - Japanese energy policy before March 2011}

Figure 5 shows the time history of Japanese energy consumption from 1950 to 2005, together with its primary sources. This figure clearly illustrates the economic expansion and the accompanying annual increase of about $8 \%$ in energy consumption during the latter half of the 1950s and throughout the decade of the 1960s. After 1970, the trend was approaching a saturation with two bumps in 1973 and 1982 triggered by the so-called "oil-shock" due to the oil embargo by the OPEC countries after the Middle-East War. The latter half of 1980's had seen a gradual expansion, but it saturated after 1990 with the subsequent years being called in Japan as "The lost 20 years".

The main primary energy source for the initial period of the 1960s expansion was, (as seen in fig. 5,) firstly coal, followed by oil especially after the latter half of the 1960s. This trend has continued to the present time, with fossil fuels, including natural gas, amounting for more than $80 \%$ of all primary energy sources.

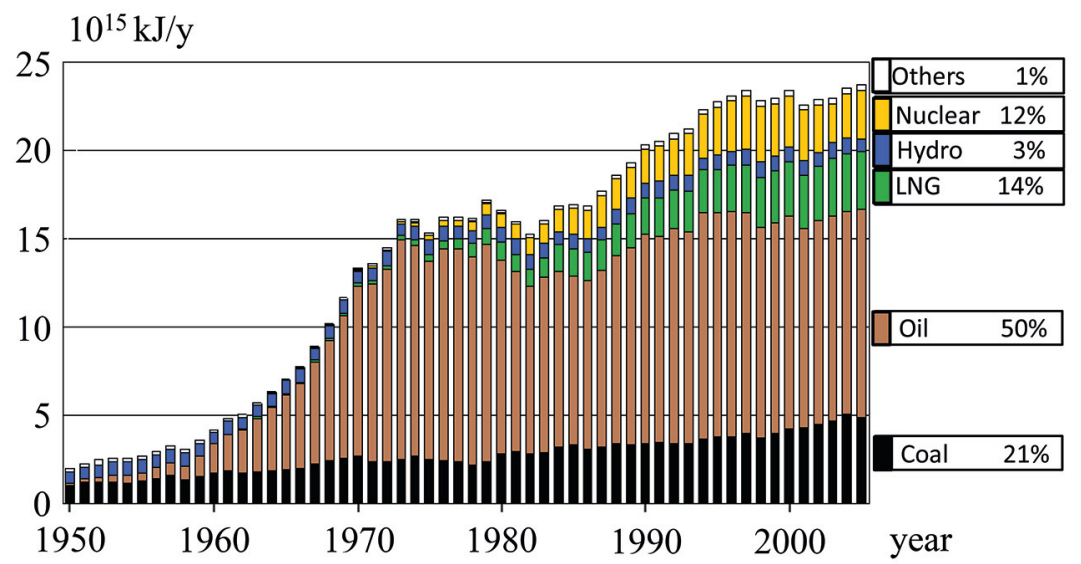

Fig. 5. - Time history of Japanese primary energy consumption together with its energy sources 1950-2005. Reconstructed from the figure released from the Energy Conservation Center, Japan on 15th February 2007. Note the distinction between the primary energy consumption shown here with the final energy consumption (energy use), the latter primarily discussed in sect. $\mathbf{5}$. 
Nuclear energy took off at the beginning of the 1970s, as in most western industrialized countries, by introduction of technologies developed and commercialized, mainly by Westinghouse and General Electric of USA. The Japanese policy on nuclear energy had been based on "Long-range plans" which had been endorsed by the government at several stages of pivotal importance. For example, a plan of 1982 was adopted just after the two oil crises by saying " $90 \mathrm{GW}$ of nuclear power by the year 2000", and that of 1987 just after the Chernobyl accident by proposing "100 GW of nuclear power by the year 2030" which was reaffirmed in the plan of 1994 . We see that the last number of $100 \mathrm{GW}$ was more than double the actual nuclear capacity (about $49 \mathrm{GW}$ from 54 nuclear reactors) at the time of the Fukushima Dai-ichi nuclear accident in 2011.

This attitude towards nuclear energy was highlighted by the Prime Minister's speech at the United Nations Summit on Climate Change [15] in September 2009 (just after his election victory). He proposed a $25 \%$ reduction of the $\mathrm{CO}_{2}$ gas emission by the year 2020 compared with that for 1990, by introducing 13 new nuclear reactors, declaring "With the change of government, as Prime Minister of Japan, I will now seek to unite our efforts to address current and future global climate change, with due consideration of the warnings of science".

\section{4. - Turmoil in Japanese energy policy after March 2011}

This is not the place to comment about the political situation in Japan, but the author wants to emphasize the fact that Japan has been experiencing the "Lost 20 years" since the burst of the economic bubble in the year 1990 and has since entered an era of deep despair of people, spurred by "Declining population combined with less and less younger generations". During these 20 years, political situations were very turbulent with many changes of governments one after another. All government measures to stimulate the economy to try to get out from the slump had turned out to be fruitless with the resultant mounting deficit of more than double the Japanese GDP (the deficit of about 10 trillion US\$, which is on average $80000 \mathrm{US} \$ /$ person). People had become irritated with the governments' poor performances during the two decades. Then came the fateful date of 11th March 2011!

The turmoil in politics described above was "well" matched by that of the energy policy of Japan during the three years after the 2011 accident. Although the government in the period before March 2011 had defined the energy policy of Japan to 2020 and beyond by being heavily dependent on nuclear energy, it was swiftly thrown away after the Fukushima accident to say that all nuclear reactors should terminate operation by the 2030's! However, this policy had a lifetime of only about one year, when the government was badly beaten at the Lower House election in December 2012.

The newly formed government has since been very careful not to say anything provocative to people and to try to conceal their real intentions. Although they say something like "Nuclear reactors are to be abolished as soon as possible", the resultant policies have been evident from their decisions, such as "Resumptions of reactor operations as soon as the Nuclear Regulation Authority declares their decision of meeting their safety stan- 


\section{EPJ Web of Conferences}

dards combined with agreement of the local government of each reactor" or "Top-sales by the prime minister to market nuclear power stations to various countries, such as Turkey or Vietnam". In their "Fundamental Energy Plan", approved on 11th April 2014 by the cabinet meeting, nuclear energy was labelled as "Bearing the base load of electricity production". Also, the fast-breeder reactor (FBR) project called "Monjyu", the operation of which has been stopped since 1995 due to sodium leakage with subsequent various negligence of regulations and which was almost being cancelled by the previous government, has been kept in this Plan with more emphasis on nuclear transmutation of long-lived radioactive waste in addition to plutonium breeding.

It is the author's feeling that the present government must be behaving like this in order to try to buy time, which is the only way out for this country before finally settling the issue without provocating the very strong anti-nuclear feeling of the people. They tend to think that Japan could not sustain the present lifestyle and position in the world because it is so heavily dependent on imports (96\%) of primary energy sources (cf., fig. 5), together with the fact that fossil fuels would have to be almost completely eliminated in the next few decades, and PV and wind energies would be too limited for this over-populated country and too unreliable because of their intermittent character. However, this discussion will be continued in the next section.

\section{5. - A personal projection of a realistic energy option for Japan to 2050}

Since the Fukushima Dai-ichi nuclear accident, opinions appearing in news media and/or expressed in academic circles have been deeply split into two groups. The first group consists of anti-nuclear people who think nuclear energy is beyond mankind's control and we have to live without it accepting any personal and national sacrifices. The second group contains pro-nuclear people who think that we have to rely on nuclear energy under the strictest regulations in order to be able to maintain a reasonable level of living standards together with energy consumption compatible with the reduction of $\mathrm{CO}_{2}$ emission. The first group receives the overwhelming support of the people, while the latter group sounds more realistic but fails to get strong support. Here lies the fundamental question of how one sees his or her life, and it is a matter of philosophy of each individual to define one's way of life.

In order to resolve this difficult question, we first have to realize the present situation regarding energy on which one may be able to chart everyone's future. What the author wants to do in this chapter is to try to visualize the situation for Japan from now to 2050. The adopted methodology may be useful for any industrialized country in the world.

5•1. The approach. - In the following, the author describes his arguments shown in depth in his book [16] using the MacKay's unit kWh/person/day [6]. Japan consumed $1.4 \times 10^{19}$ Joule/y on average just after the 2011 nuclear accident. This is converted first by dividing the above value by the Japanese population and by the number of days in a year, as $1.4 \times 10^{19} /\left(1.3 \times 10^{8} \times 365\right)=3.0 \times 10^{8} \mathrm{~J} /$ person/day. Because 
$1 \mathrm{kWh}\left(=1 \times 10^{3} \mathrm{Wh}=1 \times 10^{3} \mathrm{~J} / \mathrm{s} \times 60 \times 60\right)$ corresponds to $3.6 \times 10^{6} \mathrm{~J}$, one gets $3.0 \times 10^{8} / 3.6 \times 10^{6}=83 \mathrm{kWh} /$ person $/$ day .

Japanese citizens consume about half as much energy as those in the USA who use $157 \mathrm{kWh} /$ person/day. In fact, an average citizen in all industrialized countries in the world, except for USA, Canada and Australia, consumes about the same amount of energy, such as France ( $87 \mathrm{kWh} /$ person/day), Germany ( $85 \mathrm{kWh} /$ person/day) and the UK ( $63 \mathrm{kWh} /$ person/day), to take just a few examples. Energy consumptions in this unit in emerging countries are naturally lower than these values (for example, $43 \mathrm{kWh} /$ person/day for China and $13 \mathrm{kWh} /$ person/day for India), but their values are rapidly increasing, aiming at the above values for industrialized countries.

The distribution of the above value of $83 \mathrm{kWh} /$ person/day for Japan among various sectors is as follows (rounded off to the nearest whole numbers): $43 \%$ for industry (36 kWh/person/day), 14\% for household (12 kWh/person/day), 20\% for offices/services (17 kWh/person/day) and $24 \%$ for transportation $(20 \mathrm{kWh} /$ person/day).

$5 \cdot 2$. The present Japanese status and a projection to 2050. - In fig. 6, the above value of $83 \mathrm{kWh} /$ person/day is shown, taking the year 2011, the year of the nuclear accident, as the starting point.

It is to be noted that the energy use through electricity is only about one quarter, and the rest is by direct uses, such as gasoline for automobiles and oil for house/office heating. The primary energy consumption of Japan just before the year 2011 was $2.1 \times 10^{19} \mathrm{~J} / \mathrm{y}$ (cf., fig. 5) and its sources were fossil fuels by $83 \%$, followed by nuclear energy with $11 \%$, hydroelectricity with $3 \%$ and others (geothermal, PV, wind and others) with $3 \%$. This

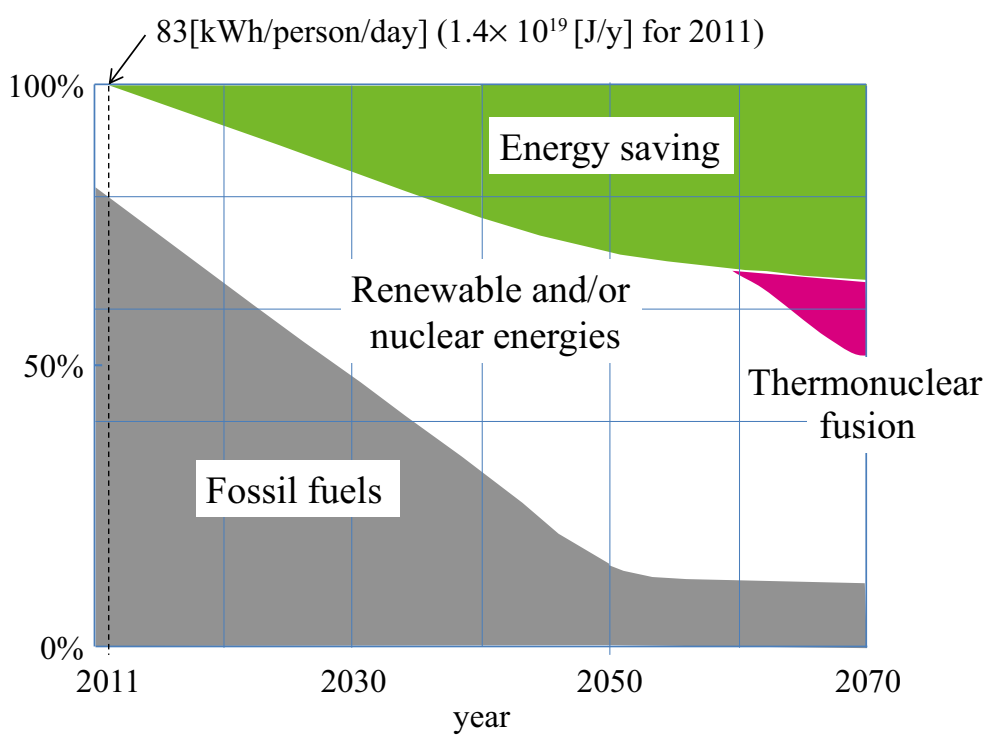

Fig. 6. - A possible scenario of the Japanese energy consumption to 2050 [16]. "Thermonuclear fusion" is described later in sect. $5 \cdot 7$. 


\section{EPJ Web of Conferences}

value of $2.1 \times 10^{19} \mathrm{~J} / \mathrm{y}$ corresponded to $124 \mathrm{kWh} /$ person/day, which was higher than the above $83 \mathrm{kWh} /$ person/day by about $50 \%$. This is mainly due to the fact that the conversion efficiency from thermal to electrical energies is only about $40 \%$. We use the final consumption of $83 \mathrm{kWh} /$ person/day in fig. 6 for two reasons as follows: Firstly, thermal power plants burning fossil fuels would have to be almost completely eliminated by 2050 , at least from industrialized countries, together with the uncertainty related with thermal plants based on nuclear energy. And secondly, newly emerging primary-energy sources, such as PV and wind, generate electricity directly and do not require energy conversion.

In order to project the energy consumption of a nation for several decades into the future, there are many uncertainties, one of which is the population change (the Japanese population is anticipated to decrease by about $30 \%$ by 2050). A big advantage of using the unit $\mathrm{kWh} /$ person/day is that this effect of the population change can be eliminated.

Now, two factors have to be considered for the future energy projection; the first is how one may project the energy saving, and the other is how one should see the reduction of reliance on fossil fuels during that period.

For the former, some say that savings as much as $50 \%$ should be possible. However, the author assumes that $30 \%$ reduction may be more reasonable, taking into account the fact that there was already a $13 \%$ reduction in the value of $83 \mathrm{kWh} /$ person/day compared with the value before the 2011 accident of $92 \mathrm{kWh} /$ person/day. In deriving this $30 \%$ reduction (to $58 \mathrm{kWh} /$ person/day), the author has assumed a significant reduction in industry and transportation, expecting efficiency improvements (such as increased use of electric vehicles). However, household and service sectors are assumed to retain almost their present values in $\mathrm{kWh} /$ person/day bearing in mind that increased energy needs in a rapidly aging society will cancel efficiency improvements in, e.g., electrical appliances. The resulting distribution among sectors is as follows: $38 \%$ for industry (22 kWh/person/day), 19\% for household (11 kWh/person/day), $26 \%$ for offices/services (15 kWh/person/day) and $16 \%$ for transportation $(9 \mathrm{kWh} /$ person/day).

It is important to reduce the use of fossil fuels, which are the dominant primary energy source for industrialized countries amounting to about $80 \%$ (it is noted that although the contribution of fossil fuels in the primary energy consumption is above $80 \%$, that in the final energy use is reduced due to losses in thermal power plants). Fossil fuels are geographically localized (often in politically unstable regions) and they have limited distribution on the Earth. This, along with the greenhouse effect resulting from their use, requires us to reduce drastically our reliance on them. The IPCC (Intergovernmental Panel on Climate Change) projects that a necessary reduction worldwide by $50 \%$ compared with the present consumption is required by 2050 in order to limit global warming to less than $2{ }^{\circ} \mathrm{C}$ of the level before the industrial revolution in order to avoid catastrophic effects on the environment. Because industrialized countries have so far benefitted much from the use of fossil fuels, they would have to bear most of the burden, probably amounting to a reduction of almost $90 \%$ by 2050 , while allowing emerging economies to try to meet their increased energy demands partly by increasing their use of fossil fuels. Recently, IPCC has cited [17] that industrialized countries have 
to reduce $\mathrm{CO}_{2}$ emissions by $41-72 \%$ by 2030 compared with the emission values of 2010 .

These two projections are drawn in fig. 6 for Japan as two smooth lines, and the middle area shown in white has to be supplied by either renewables or nuclear energy, or an appropriate combination of the two. As we see from this figure, we need to replace $60 \%$ of the present consumption of $83 \mathrm{kWh} /$ person/day, namely $50 \mathrm{kWh} /$ person/day, by 2050 using renewable and nuclear energy sources.

It is to be noted how large $1 \mathrm{kWh} /$ person/day is for Japan from its population and the number of days in a year, yielding $1 \mathrm{kWh} /$ person/day $\times 1.3 \times 10^{8} \times 365=47 \mathrm{TWh} / \mathrm{y}$, which is about $5 \%$ of the present electricity production of $1.1 \times 10^{12} \mathrm{kWh} / \mathrm{y}$. Alternatively, $1 \mathrm{kWh} /$ person/day implies an average output of $5.4 \mathrm{GW}(=1 \mathrm{kWh} /$ person/day $\times 1.3 \times$ $\left.10^{8} / 24\right)$, namely about 5 units of an electric power station having a relatively large output of $1 \mathrm{GW}$ each.

Let us think of renewable and nuclear energies in detail in the following two sections.

5·3. Renewable energies. - Presently, the largest contribution of renewable energies in Japan comes from hydroelectricity, amounting to $3 \mathrm{kWh} /$ person/day. Because most potential sites have already been developed, there seems to be no further scope of exploitation except for small water mills which would never match the level of $1 \mathrm{kWh} /$ person/day. The present geothermal energy in Japan, though believed to be one of the biggest geothermal electricity producers in the world, produces only $0.1 \mathrm{kWh} /$ person/day. The maximum possible potential in future is estimated to be about $2 \mathrm{kWh} /$ person/day. The uses of biomass and waste are hopeless in this over-crowded country in terms of contributing in the order of $\mathrm{kWh} /$ person/day. Contributions of future wave and tide energies are difficult to estimate at the present primitive stage of their development, but all these sources combined will, by the author's estimate, not exceed $5 \mathrm{kWh} /$ person/day in 2050 . Therefore, we take the value of the maximum obtainable renewable energy from these sources combined in 2050 to be $10 \mathrm{kWh} /$ person/day.

Next, we discuss the potential of solar and wind energy, the biggest hopes of renewable energy in any country, where the limiting factors for Japan are its limited land area $\left(380000 \mathrm{~km}^{2}\right)$ and its large population $\left(1.3 \times 10^{8}\right)$.

1) Potential of solar PV and wind energy

Regarding solar PV energy, we see that $15 \mathrm{~W} / \mathrm{m}^{2}$ is obtainable for the Japanese environment [16], which is an averaged value over four seasons, day and night, and all weather conditions with an assumed conversion efficiency of PV cells of $10 \%$ (higher efficiencies are possible, but their potential use in the market cannot be foreseen). This implies that one can get $15 \times 24 \mathrm{Wh} / \mathrm{m}^{2} /$ day $=0.36 \mathrm{kWh} / \mathrm{m}^{2} /$ day. Dividing the Japanese land area of $3.8 \times 10^{11} \mathrm{~m}^{2}$ by the population of $1.3 \times 10^{8}$, one gets the inverse of the population density to be $2,950 \mathrm{~m}^{2} /$ person. If all the land area were to be devoted for solar PV, Japan would get as much as $0.36 \times 2950=1060 \mathrm{kWh} /$ person/day. This implies that Japan could meet the target value of $40 \mathrm{kWh} /$ person/day by 2050 , if it devoted about $4 \%$ of its land area for solar PV parks. However, one has to bear in mind that the proportion of the flat area against the total area is only about $15 \%$, and this flat area is 


\section{EPJ Web of Conferences}

already mostly occupied by houses, factories, offices, and rice and vegetable fields. This point is discussed in the next point 2).

Regarding wind energy, we see that $2 \mathrm{~W} / \mathrm{m}^{2}$ from onshore and $3 \mathrm{~W} / \mathrm{m}^{2}$ from offshore are obtainable for the Japanese environment, which are again averaged values over all conditions [16]. This implies that one can get $2 \times 24 \mathrm{Wh} / \mathrm{m}^{2} /$ day $=0.048 \mathrm{kWh} / \mathrm{m}^{2} /$ day from onshore and $3 \times 24 \mathrm{Wh} / \mathrm{m}^{2} /$ day $=0.072 \mathrm{kWh} / \mathrm{m}^{2} /$ day from offshore. If all the land area and an equal area of ocean were to be devoted for wind parks, Japan would get as much as $0.048 \times 2,950=142 \mathrm{kWh} /$ person/day from onshore and $0.072 \times 2,950=$ $212 \mathrm{kWh} /$ person/day from offshore. This implies that Japan could meet the target value of $40 \mathrm{kWh} /$ person/day by 2050, if it devoted about $11 \%$ of its combined land and ocean area for onshore and offshore wind parks.

2) Reasonable estimates of solar PV and wind energies to 2050

First, we show the present scales of solar PV and wind energy in Japan, after much expansion due to the introduction of a German-type FIT (feed-in-tariff) system after 2012 as one result of the nuclear accident and the resultant electricity shortage. By the end of 2012, the installed solar PV capacity was $5.5 \times 10^{6} \mathrm{~kW}$ and that of wind energy was $2.6 \times 10^{6} \mathrm{~kW}$, which produced respectively $5.8 \times 10^{9} \mathrm{kWh} / \mathrm{y}$ and $6.8 \times 10^{9} \mathrm{kWh} / \mathrm{y}$ by taking into account their respective capacity factors of 0.12 and 0.30 . These combined values yield about $1.2 \%$ of the present annual electricity production of $1.1 \times 10^{12} \mathrm{kWh}$, implying that the present level is still "primordial". However, the business sector has been rapidly expanding its production capacities, e.g. a leading wind turbine company has started to collaborate with a Danish company, while installations of large PV parks, called "Mega-solar", have been increasing due to the above FIT scheme.

In order to project from now to 2050, what sort of land and ocean areas could Japan devote for solar PV and wind parks? In this respect, useful information is gained from an advertisement that appeared in national newspapers just after the 2011 accident. This proposed that we should exploit usable areas for solar PV parks, where the total usable area was quoted as $2.2 \times 10^{9} \mathrm{~m}^{2}$ (roofs of public buildings: $3.5 \times 10^{8} \mathrm{~m}^{2}$, and power stations/factories/distribution centres: $4.3 \times 10^{8} \mathrm{~m}^{2}$; under or un-used land: $4.1 \times 10^{8} \mathrm{~m}^{2}$, and rice fields that are not used any more: $1.05 \times 10^{9} \mathrm{~m}^{2}$ ). This value of $2.2 \times 10^{9} \mathrm{~m}^{2}$ is $0.6 \%$ of the total land area of $3.8 \times 10^{11} \mathrm{~m}^{2}$. In countries where mountains are relatively low, much like rolling hills, one may also use these places for PV or wind parks. However, because Japan is shaped by steep mountains, it is difficult to realize this possibility. In addition, there is a concern for decreased absorption of $\mathrm{CO}_{2}$ by plants and a damage of landscape if a sizable portion of the mountain area were to be covered by PV panels and wind turbines.

From these backgrounds, the author estimates the maximum land area available for solar PV parks to $1 \%$ of the total land area, meaning that the maximum solar PV potential would be about $10 \mathrm{kWh} /$ person/day. It is to be noted that this area may also be used for wind parks, discounting the fact that windmills cast small shadow areas over $\mathrm{PV}$ cells, yielding $1.4 \mathrm{kWh} /$ person/day. If a 5 times bigger ocean area, corresponding to $5 \%$ of the land area, which may be a large overestimate, could be devoted to offshore 
wind parks, one would get as much as $11 \mathrm{kWh} /$ person/day.

Adding up these values yields about $23 \mathrm{kWh} /$ person/day, namely about $58 \%$ of the target value of $40 \mathrm{kWh} /$ person/day being supplied from solar PV and wind parks. However, it has to be kept in mind that this is based on very optimistic assumptions that may turn out to be difficult to realize. It is thus stressed that renewable energy alone may be difficult to meet the target value.

5*4. Nuclear energy. - In the strong anti-nuclear sentiment in Japan that prevailed after the Fukushima Dai-ichi nuclear accident, how could one project the future of nuclear energy? A recent big development in this respect is a district court ruling on 21st May 2014, which for the first time after the 2011 accident ordered an electric power company not to resume operations for its two reactors, located near to Osaka. The ruling stated that the assumed acceleration of $700 \mathrm{Gal}\left(7 \mathrm{~m} / \mathrm{s}^{2}\right)$ due to an earthquake was groundless in the light of the experience of the Fukushima Dai-ichi nuclear accident. A professor emeritus of nuclear engineering commented in a daily newspaper "This is the verdict of no more nuclear energy in this country". The electric power company has immediately appealed to a higher court to reverse the decision, and the issue has not been settled, but people have felt the renewed impact of the 2011 nuclear accident

Putting these judicial and political (as described in sect. 4) arguments aside, let us start from the fact that nuclear reactors produced $6 \mathrm{kWh} /$ person/day before the 2011 accident. This output has been almost completely stopped for more than three years now, implying that the missing $6 \mathrm{kWh} /$ person/day have had to be supplemented by fossil fuels (one of the main reasons for Japan to have experienced an unprecedentedly large trade deficit for the first time since the turbulent period just after the Second World War). Then, what amount of nuclear energy one could project in the white area of fig. 6 in $2050 ?$

The most optimistic projection may be to double the above $6 \mathrm{kWh} /$ person/day to $12 \mathrm{kWh} /$ person/day by means of replacing old reactors (some have electricity outputs of less than $0.5 \mathrm{GW}$ ) with newer/safer ones having an output of about $1.5 \mathrm{GW}$. The opposite side of the spectrum is to project, as the previous government once proposed, that there would be no reactors in existence by 2050 .

Let us see next the outcome of the projections described in the last two sections.

5.5. Possible scenarios to 2050. - Based on the "Numbers" derived in sects. 5:3 and $\mathbf{5} \cdot$, one gets the maximum possible value of $23 \mathrm{kWh} /$ person/day (from solar PV and wind parks $)+12 \mathrm{kWh} /$ person/day (from nuclear energy) $=35[\mathrm{kWh} /$ person/day $]$. This is less than $40 \mathrm{kWh} /$ person/day, which is necessary to sustain the society as described in sect. $5 \cdot 2$ of $50 \mathrm{kWh} /$ person/day minus $10 \mathrm{kWh} /$ person/day, the last number being expected from renewable energies other than solar PV and wind as described at the beginning of sect. $5 \cdot 3$. 


\section{EPJ Web of Conferences}

How optimistic is this scenario may be argued from various viewpoints as follows:

1) Necessary investments for variable sources of solar PV and wind

The maximum possible energy of $23 \mathrm{kWh} /$ person/day from solar PV and wind parks is obtained as being limited only by the overcrowded land area without any regards to other factors. The most obvious missing factor is the cost to realize this target value, namely the costs for investment on production and installation of solar PV and wind energy systems, and on the infrastructure to bring the produced energy to consumers. Regarding the latter factor of infrastructure, Wagner [18] pointed out that stresses on grids and the surplus power become very large and the capacity factor of back-up thermal power becomes very low once the contributions from intermittent sources, namely from solar PV and wind energies, exceed $40 \%$ of the total load. This is particularly severe for Japan, an island country isolated from the rest of the world with no grid connection to the outside, unlike European countries.

Storage of electrical energy by some means eases the use of intermittent energy from renewable sources. In this respect, pumped storage is a proven technology. However, Japan has almost exhausted its potential sites at the present capacity of about $26 \mathrm{GW}$, which is about $8.6 \%$ of the total electricity generating capacity of $303 \mathrm{GW}$. Therefore, in order to meet the above target of more than $40 \%$ of the total load, in particular in the ever increasing proportion of electricity in the final energy use, Japan needs a completely different technology, e.g. preparing a spare battery for each electric vehicle in future, to be stored at a charging station for electricity storage/discharge as required [6], or using surplus energy to convert $\mathrm{CO}_{2}$ and $\mathrm{H}_{2} \mathrm{O}$ into hydrocarbons which may subsequently be used as a fuel [19].

Regarding the costs for investment on production of solar PV and wind energy systems, the burden of the FIT system has not been felt yet in Japan. For example, an average household of four persons (parents and two children) consuming $300 \mathrm{kWh} / \mathrm{month}$ pays about 7000 Yen/month (about 50 Euros/month) in 2013, of which 108 Yen (about 0.8 Euro) are for the FIT subsidy. At the end of March 2014, the government agency announced that the FIT charge would be more than doubled from the above value to 225 Yen/month (about 1.6 Euros/month), as a result of increase of the PV installation from $1.2 \times 10^{7} \mathrm{~kW}$ at the end of 2013 to $2.0 \times 10^{7} \mathrm{~kW}$ at the end of 2014 . The capacity factor of 0.12 for solar PV means that an installed capacity of $2.0 \times 10^{7} \mathrm{~kW}$ produces $2.0 \times 10^{7} \times 0.12 \times 24 \times 30=1.7 \times 10^{9} \mathrm{kWh} /$ month, which is $1.7 \%$ of the total electricity production in Japan of $1.0 \times 10^{11} \mathrm{kWh} /$ month. It is noted that the amounts of the FIT charges for other renewable sources are negligibly small. At this stage, therefore, an average Japanese household is not feeling a similar burden as their German counterpart, who paid about 15.5 Euros/month in 2013 for the FIT charge by an average household (paying 81 Euros/month for an electricity bill [20]) for the production of its electricity of about $14 \%$ from both PV and wind parks. However, Japanese may start to feel a similar strain as Germans do, if the present trend will continue for the next few years. 
2) Uncertainties surrounding the nuclear energy

Replacements of existing old and small reactors with newer/safer and larger ones, yielding the ultimate output of $12 \mathrm{kWh} /$ person/day, sound reasonable, but the present atmosphere in the Japanese attitude toward nuclear energy expressed in various opinion polls is very negative. In addition, the newly formed Nuclear Regulation Authority insists that some reactors that are located on land that has faults underneath would not be allowed to resume operations any more. Therefore, to keep the pre-accident value of $6 \mathrm{kWh} /$ person/day looks difficult, even allowing for some reactors to be replaced with newer/safer and bigger ones.

Personally, the author projects that the most optimistic supply from nuclear energy to 2050 would be $8 \mathrm{kWh} /$ person/day. This implies that there will exist a shortfall of well above $10 \mathrm{kWh} /$ person/day, because the energy from solar PV and wind parks of $23 \mathrm{kWh} /$ person/day is based on rather optimistic estimates as described in sect. $5 \cdot 3$.

In addition to the above arguments, there has always been a persistent concern of handling and storage of nuclear wastes. In Japan, in particular, the policy of fuel recycling will have to be reassessed after many failures at the reprocessing plants at Rokkasho, Aomori Prefecture, resulting in accumulation of a large amount of used fuels piled up at each nuclear power station. Added to this is the necessity to decide how to proceed with the vast amount of high- and low-radioactive materials existing not only in the Fukushima Dai-ichi nuclear power station itself but also in surrounding vast areas, to be somehow collected, treated and stored aiming at decommissioning after the nuclear accident for the coming few decades. These issues will have to be solved even if nuclear energy will eventually be abandoned in Japan.

5.6. Possible remedies to save the situation. - If the middle white area of $50 \mathrm{kWh} /$ person/day in 2050 in fig. 6 would not be covered by a combination of solar $\mathrm{PV}$, wind and nuclear energy as the most possible outcome from the discussions in the above sects. $\mathbf{5} \cdot \mathbf{1 - 5} \cdot \mathbf{5}$, what options might be possible to save the situation for Japan?

Obviously, there are two possibilities, namely first to increase energy saving from the present assumption of $30 \%$ and secondly to retain more energy than $10 \%$ from fossil fuels. The former would ensure quite drastic changes in the way of life for all average Japanese, and it is a topic to be discussed from political/sociological/philosophical standpoints, which is beyond the scope of the author.

Regarding the latter possibility, one would be forced to face the ever-increasing danger of global warming, as the Fifth Report from IPCC issued in 2013-14 insists from various symptoms appearing on the planet, the most noticeable being the fast and accelerating losses of the Arctic and Greenland ice-sheets. Therefore, one would have to increase the use of fossil fuels without releasing $\mathrm{CO}_{2}$ gas into atmosphere. The well-known solution is to resort to the technology of CCS (Carbon Capture and Storage). However, this technology is still at a development stage, and requires a lot of investment for further development and commercial deployment. In addition, the operation of its equipment would consume about $30 \%$ of the energy contained in fossil fuels. In any case, Japan 


\section{EPJ Web of Conferences}

needs to participate in the world-wide effort to bring the technology into practical use.

Moreover, CCS has also the drawback of possible environmental effect due to leaks of stored $\mathrm{CO}_{2}$, either geologically or in oceans. Above all, this option is possible only temporarily, because of the limited supply of fossil fuels in future.

5.7. A possible role that fusion energy may play. - At this stage of descriptions, as a researcher once seriously engaged in thermonuclear fusion, the author is tempted to say a word or two about a possible role that fusion energy may play.

The ITER (International Thermonuclear Experimental Reactor) project, "The Engineering Development Reactor", is its flagship program being built in France as an international collaboration of Japan, EU, USA, Russia, China, South-Korea and India. If this project will turn out to be successful and another project of materials developments, being carried out separately, will also go well, the Demonstration Power (DEMO) plant will be built around 2045. If this DEMO program also goes well, a Commercial Power Plant will follow and will start to supply electricity to grids around 2060. This is illustrated in fig. 6 in the latter half of this century with a rather optimistic expansion after 2060 of an increase of about $1.5 \mathrm{kWh} /$ person/day per year for Japan, which corresponds to 7 fusion reactors/year having an electrical output of $1 \mathrm{GW}$ each for the then Japanese population of about 100 million people. This introduction of fusion energy may change the energy scene at the latter half of this century for the whole world.

However, the above time scale looks too late for fusion to arrive in time for mankind and more generally for the ecological system of the planet. If fusion is to play a useful role for society, its development needs to be much speeded up, and hopefully to start supplying electricity well before 2040 as is evident from fig. 6. Most fusion researchers may say that realization of fusion energy within 30 years from now is unrealistic. However, bearing in mind the present situations for mankind, one has to realize that this possibility must be pursued to the extremes. We may remember the famous phrase by L. Artsimovich, a fusion pioneer of the former Soviet Union, "Fusion will be there when society needs it" [21]. Japan, which tends to boast itself (at least at home by politicians) as "The world leader in technology renovation/revolution", needs to play a key role for such a pursuit. It is the author's belief that this endeavor is worth pushing forward as the biggest project in the 21 st century with all its resources to save mankind.

\section{6. - Summary}

It has been the author's intention to convey two messages to readers of this article, namely 1) to explain about the background, the event and the resultant casualties of the 2011 nuclear accident, and 2) to chart possible energy options for Japan from the present to the future. Each item is summarized below, but the overall picture of the Japanese energy scene had been rather quiet in the rapid economic recovery and expansion from 1955 to 1990 , followed by a turbulent period of about 20 years politically and in energy policy, during which the 2011 accident occurred. 
Item 1) may be summarized as follows:

The phrase that is expressed or written most often by people, especially executives and directors of TEPCO, is "A natural disaster beyond imagination". Indeed, it was a very rare event. However, it is now known by everybody that an earthquake of a similar size occurred in the 9th century from various records (named as "the Jo-gan big earthquake" occurred on 7th July 869, with the estimated magnitude of more than 8.3 in the Richter scale), resulting in devastating damage and losses of lives. It is to be regretted that the persons in charge of planning, building and running nuclear reactors did not fully recognize their responsibility and expand their imagination for what could happen if a similar event of about only 1200 years ago would have occurred again. We, as laypersons, used to hear that any severe accident would occur less than once in a million years for a nuclear reactor, and 1200 years are three orders of magnitude smaller than this one million years!

One has to delve deeper to explore the cause(s) of this very severe accident "Made in Japan" and to try to find possible remedies not to cause a similar accident again. However, it is regrettable that any serious pursuit resulting in any policy decision with meaningful consequences has not been reached since the four reports of investigation committees into the nuclear accident were released in 2012.

In short, it is the author's belief that "Importance of civilian control" may be the biggest lesson that Japan should have learned from this grueling experience. The term "Civilian control" is usually applied to military matters. In fact, the most severe experience for Japan before the 2011 nuclear accident was the Second World War. The path leading to Japan's entry into the Second World War in December 1941 had been paved by the military inner circle. The War itself was fought without informing people what had been happening on the battle-fields, namely shrouding all information inside the circle, and releasing only favorable stories to the outside which have become infamously known as "Daihon-ei Happyou" (literally, "News release from the Imperial General Headquarters").

There was a similar inner circle of Genshiryokumura village which had decided all directions and subsequent policies on nuclear energy by themselves without letting people know what had been happening or could happen in the worst case in reactors, thus shrouding all information inside the circle and releasing only favorable stories to outside. Evidently, "Civilian control" was badly missing in this structure, exactly similarly as for the case leading to and during the Second World War in Japan.

After the Second World War, "Civilian control" has been granted to people, by the newly introduced Japanese Constitution of 1947. However, due to very low polling rates for national and regional elections, rating less than half for many elections in recent years, it has been increasingly difficult for the "Civilian control" to function properly.

On the other hand, after the nuclear accident of 2011, the newly formed Nuclear Regulation Authority has started functioning since its formation on 19th September 2012. However, many people tend to think that these ("difficult") things related with nuclear energy be beyond them, thus making "Civilian control" in this case devoid of its essence. The burden of what sort of path Japan should pursue in its policy on nuclear 


\section{EPJ Web of Conferences}

energy has to be borne by its people, who should understand their responsibilities in this respect from now on. Simply giving a negative response to media polls may not be sufficient.

Item 2) may be summarized as follows:

If one would try to find any positive side of the 2011 nuclear accident summarized above in 1), it may be the fact that everybody was forced to have realized the importance of energy for society and its saving. Previously, energy was generally treated similarly as "like water" in the Japanese saying, with the background of Japan in an environment of almost limitless resources of water. However, energy has now been started to be seen as a priceless commodity, without which any industrialized country cannot function.

Also, the warning from the IPCC about global warming due to excessive use of fossil fuels has been more and more seriously accepted by people these days, as evidenced from recent opinion polls conducted after the release of the three reports of the IPCC fifth assessment report in 2013-2014.

Therefore, most people may now understand the two constraints shown in fig. 6, namely the necessity to save energy from the above and that of drastically reducing (almost completely eliminating) the consumption of fossil fuels in the next couple of decades from below. How could one find the solution to fill the remaining white area in between the two constraints in fig. 6? The author has tried to fill in this area in sect. 5, but failed to find a viable and socially acceptable solution from the present scientific and technological backgrounds.

As such, any choice from various possibilities, such as a further drastic reduction of energy use, much more employment of renewable energies, abolition or increased use of nuclear energy, and more or less use of fossil fuels, will inevitably incur sacrifices and hardship to us. Therefore, people have themselves to bear the resulting sacrifice/burden that inevitably results from their own choice. Although there have been numerous proposals and suggestions to people about the future energy policy to be taken by renowned professors, writers and commentators/critics, these "stories" mostly lack useful criteria for people to decide their future directions, much like political manifestos. It is hoped that such proposals will be made with the resulting sacrifice/hardship that is inevitably incurred from each choice to be clearly stated in understandable terms and words for people, so that they can chart their future with confidence. This should ensure the essence of "Civilian control" on the energy policy, very suitable for any civilized country in the world of the 21st century.

$* * *$

The author wishes to thank Dr. F. Wagner, the director of the summer school, for inviting him to give this lecture, whereby "being forced to" have thoroughly studied many publications related with the Fukushima Dai-ichi nuclear accident again. Dr. Wagner also gave many useful advices for the structure and expressions of this article. He also wants to thank Dr. P. Stott for not only giving many advices of English expressions but also very useful suggestions, so that the contents of this article could have been much enhanced. He is also indebted to Dr. A. Donne for supplying him useful advices, in particular the 
information related with new possibilities of energy storage. Friends, colleagues and former students of the author have made useful contributions to this article, and he hopes to thank them all.

\section{REFERENCES}

[1] Report of the National Diet of Japan Fukushima Nuclear Accident Independent Investigation Commission (in both Japanese and English), issued on 5th July 2012, http: // warp.da.ndl.go.jp/info:ndljp/pid/3856371/naiic.go.jp/index.html.

[2] Report of the Investigation Committee on the Accident at the Fukushima Nuclear Power Stations of Tokyo Electric Power Company, Interim Report issued on 26th December 2011 and Final Report issued on 23rd July 2012 (in both Japanese and English) http://jolisfukyu.tokai-sc.jaea.go.jp/ird/sanko/hokokusyo-jp.html.

[3] Report of the Fukushima Daiichi Nuclear Power Station Disaster: Investigating the Myth and Reality, Discover 21 Co. Ltd., Tokyo, 2012 (in both Japanese and English).

[4] Report of the Investigation Committee on Fukushima Nuclear Accident, Interim Report issued on 2nd December 2011 and Final Report issued on 20th June 2012 (in Japanese) http://www.tepco.co.jp/cc/press/2012/1205628_1834.html.

[5] The fundamental energy plan of Japan: 2014 (in Japanese) http://www.enecho.meti. go.jp/category/others/basic_plan/pdf/140411.pdf.

[6] MacKay D., Sustainable energy - without the hot air (UIT, Cambridge) 2009, http:// www.withouthotair.com/cft.pdf.

[7] The government document defining three regions of radioactivity-contaminated area due to the Fukushima Dai-ichi nuclear accident (in Japanese) http://www.mext.go.jp/ b_menu/shingi/chousa/kaihatu/016/shiryo/_icsFiles/afieldfile/2013/10/02/ 1340046_4_2.pdf.

[8] KAN N., What I thought as the then prime minister during the Fukushima nuclear accident (Gentosha-Shinsho 283, Tokyo) 2012 (in Japanese).

[9] The overall summary of the Fukushima Dai-ichi Nuclear Accident and the revised plan for the nuclear plant safety by TEPCO, issued on 29th March 2013 (in Japanese) http://www.tepco.co.jp/cc/press/betu13_j/images/130329j0401.pdf.

[10] Report of the Investigation Committee by the Atomic Energy Society of Japan of the Fukushima Dai-ichi Nuclear Accident (Maruzen Publishing, Tokyo) 2014 (a book of the report published in Japanese).

[11] Climate change and nuclear power 2013 (IAEA) 2013, http://www . iaea.org/newscenter/ news/2013/climatechnagenp.html.

[12] IAEA Action Plan on Nuclear Safety (IAEA) 2011, http://www.iaea.org/newscenter/ focus/actionplan/reports/actionplanns130911.pdf.

[13] Amano Y., Statement to Fifty-Sixth Regular Session of IAEA General Conference 2012 (IAEA) 2012, http://www . iaea.org/newscenter/statements/2012/amsp2012n012.html.

[14] FunAhashi Y., Defeated war against nuclear energy - Japan repeated the defeated war at Fukushima, similar to THAT WAR (Bunshun-Shinsho 956, Tokyo) 2014 (a book published in Japanese).

[15] Hatoyama Y., "Statement by Prime Minister Yukio Hatoyama at the United Nations Summit on Climate Change", The Prime Minster's office, 2009, http://japan.kantei. go.jp/hatoyama/statement/200909/ehat_0922_e.html.

[16] Muraoka K., Energies in the coming age for Japan (Sangyo-Tosho Publishing, Tokyo) 2012 (a book published in Japanese). 


\section{EPJ Web of Conferences}

[17] The third working group report of the IPCC fifth assessment, 2014, https://www.ipcc.ch/ publications_and_data/publications_and_data_reports.shtml.

[18] Wagner F., Eur. Phys. J. Plus, 129 (2014) 20.

[19] http://www.rsc.org/images/Solar-fuels_tcm18-221433.pdf, http://www.differ.nl/sites/default/files/multimedia/organization/PI/CO2\%20 workshop $\% 20$ Intro\%20RvdS.pdf.

[20] Fact-paper on electricity prices in Germany, http://www.ostwuerttemberg.ihk.de/ downloadcenter/downloads/pdf/umwelt/Strompreise_in_Deutschland_11_2012.pdf.

[21] Braams C. M. and Stott P. E., Nuclear Fusion (Institute of Physics Publishing, Bristol and Philadelphia) 2002. 